08.1

\title{
Влияние обработки в Не:О плазме на структуру многостенных углеродных нанотрубок
}

\author{
(C) В.В. Болотов, Е.В. Князев, С.Н. Несов \\ Омский научный центр СО РАН, Омск, Россия \\ E-mail: knyazev@obisp.oscsbras.ru
}

Поступило в Редакцию 11 мая 2021г.

В окончательной редакции 30 ноября 2021 г.

Принято к публикации 30 ноября 2021 г.

\begin{abstract}
Исследована функционализация многостенных углеродных нанотрубок в Не:О плазме. Показано, что плазменная обработка приводит к удалению дефектных наружных графеновых слоев и их фрагментов вследствие окисления. Установлено, что поверхность функционализированных многостенных углеродных нанотрубок содержит большое количество нескоординированных углеродных атомов и кислородсодержащих функциональных групп. Сохранение структуры внутренних графеновых слоев нанотрубок и формирование оборванных химических связей обеспечивают уменьшение электрического сопротивления. При этом наблюдается сужение распределения значений электрического сопротивления ансамблей нанотрубок.
\end{abstract}

Ключевые слова: многостенные углеродные нанотрубки, плазменная обработка, функционализация, просвечивающая электронная микроскопия, рентгеновская фотоэлектронная спектроскопия.

DOI: 10.21883/PJTF.2022.05.52148.18864

Многостенные углеродные нанотрубки (МУНТ) являются перспективными при разработке новых материалов для производства электродов литий-ионных аккумуляторов и суперконденсаторов $[1,2]$. Высокие механические характеристики МУНТ открывают перспективу получения на их основе пористых материалов для электродов источников тока с изменяемой геометрией. При использовании МУНТ в качестве электродного материала важную роль играет сопротивление слоя нанотрубок, которое зависит как от собственного сопротивления индивидуальных МУНТ, так и от сопротивления контакта между трубками. Снижение общего сопротивления слоя нанотрубок может быть достигнуто путем присоединения функциональных кислородсодержащих групп к поверхности МУНТ [3]. Кроме того, закрепление на поверхности нанотрубок функциональных групп и комплексов способствует увеличению удельной емкости углеродных материалов за счет протекания на них окислительно-восстановительных реакций при взаимодействии с электролитом $[4,5]$. Плазменная обработка благодаря низкой энергии заряженных частиц модифицирует лишь внешние графеновые слои углеродной нанотрубки, не изменяя структуру внутренних слоев [6]. Введение реакционных газов $\left(\mathrm{O}_{2}, \mathrm{~N}_{2}, \mathrm{NH}_{3}\right.$ и т. д.) во время плазменной обработки позволяет проводить химическую направленную функционализацию поверхности МУНТ [7,8]. В настоящей работе методами просвечивающей электронной микроскопии (ПЭМ) и рентгеновской фотоэлектронной спектроскопии (РФЭС) исследована структура МУНТ после воздействия Не:O плазмы. Изучено влияние плазменной обработки на электрофизические свойства ансамблей нанотрубок.

МУНТ синтезировались методом CVD (chemical vapor deposition) по методике, описанной в [1]. Функциона- лизация слоя МУНТ проводилась в Не:О плазме мощностью $250 \mathrm{~W}$. Скорость потока газовой смеси $40 \mathrm{sccm}$, состав смеси Не : $\mathrm{O}_{2}=1: 3$. Время обработки $20 \mathrm{~s}$.

Структура МУНТ исследовалась с помощью электронного микроскопа JEOL JEM-2100. Структурнохимическое состояние углерода в стенках нанотрубок изучалось методом РФЭС на установке Surface Science Center (Riber). Возбуждение спектров проводилось с использованием немонохроматического $\mathrm{Al} K_{\alpha}$-излучения. Глубина анализа составляла не более $2 \mathrm{~nm}$. Количественный элементный анализ проводился по обзорным РФЭС-спектрам с применением метода коэффициентов элементной чувствительности.

Исследование проводимости ансамблей МУНТ осуществлялось на LCR-метре Agilent E4980. Сопротивление ограниченных ансамблей определялось по вольт-амперным характеристикам разреженных ансамблей МУНТ, расположенных между золотыми встречноштыревыми контактами.

Согласно данным ПЭМ, исходные МУНТ обладают бамбукоподобной структурой, характерной для легированных азотом нанотрубок (рис. 1,a) [1,3]. Внешний диаметр углеродных нанотрубок варьируется в диапазоне от 20 до $60 \mathrm{~nm}$. Межплоскостное расстояние между графеновыми слоями в стенках исходных МУНТ, полученное по результатам быстрого фурье-анализа изображений, составляет $\sim 0.34-0.35 \mathrm{~nm}$. Графеновые слои стенок МУНТ не имеют разрывов и существенных изгибов. Толщина стенок исходных нанотрубок меняется незначительно.

После экспозиции в плазме на внешней поверхности МУНТ наблюдаются кратеры размером $\sim 30 \mathrm{~nm}$, образованные за счет удаления крупных фрагментов графеновых слоев (рис. $1, b)$. Глубина кратеров неоднородна, на 

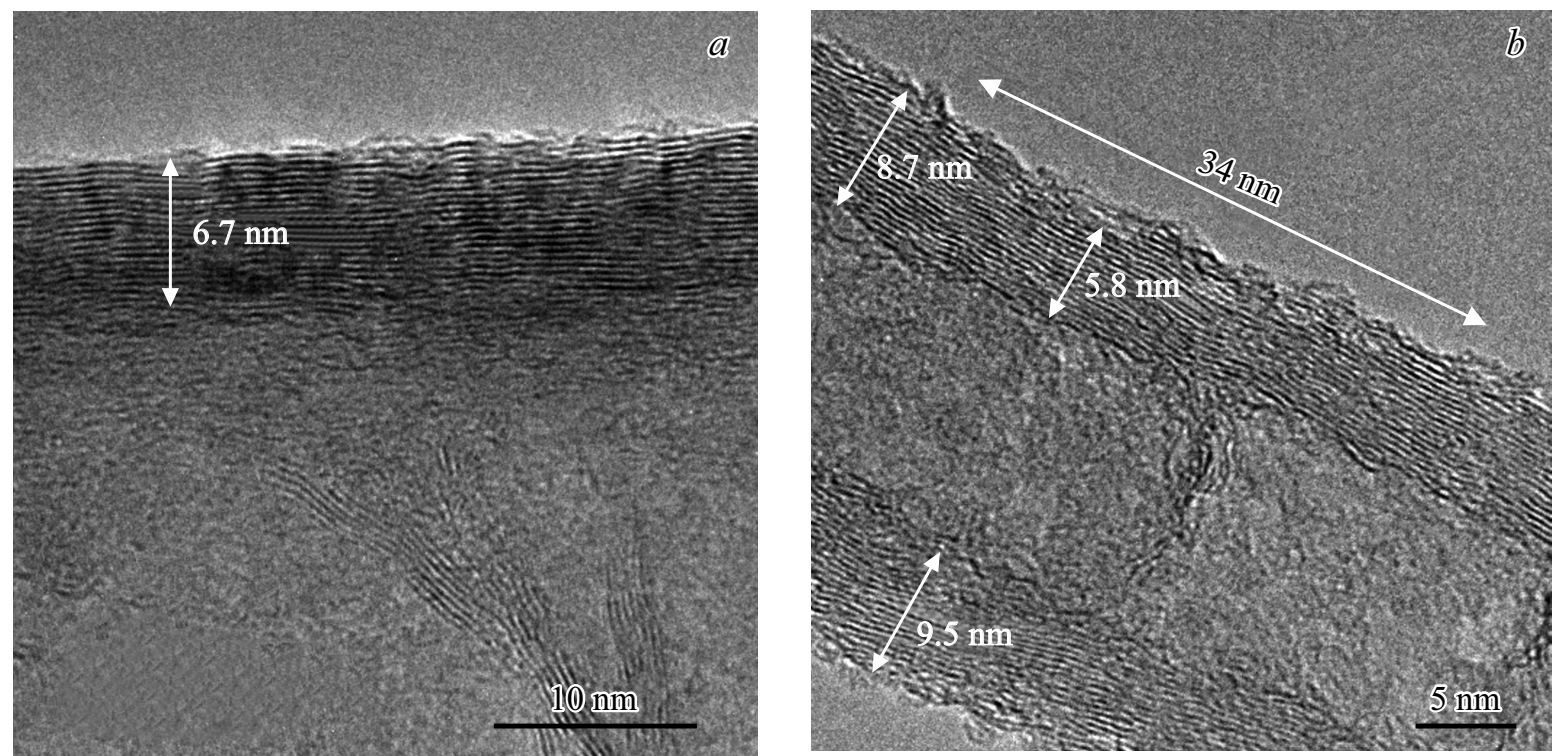

Рис. 1. ПЭМ-изображения стенки МУНТ до плазменных обработок (a) и МУНТ после обработки в плазме $(b)$.
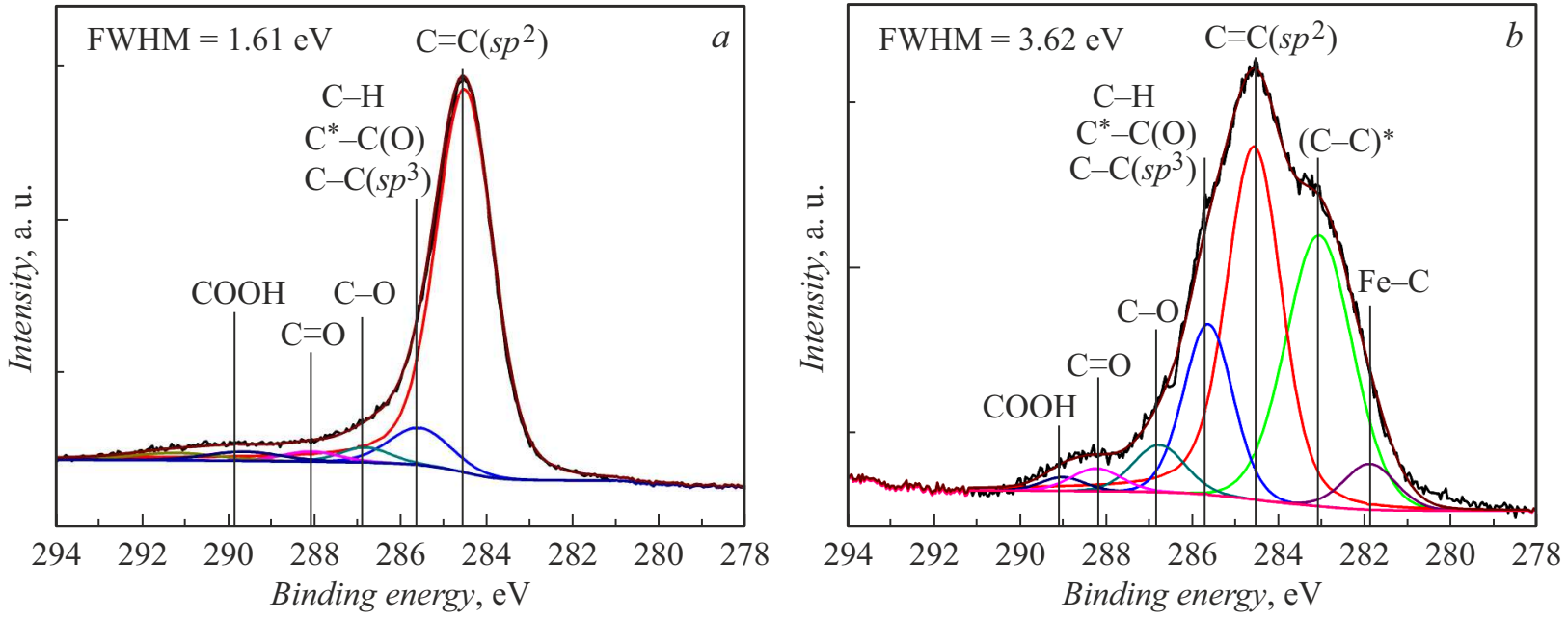

Рис. 2. РФЭС С $1 s$-спектры. $a$ - исходных МУНТ, $b-$ МУНТ после обработки в плазме.

РФЭС-анализ элементного состава исходных и обработанных в плазме МУНТ

\begin{tabular}{c|r|r|r|c}
\hline \multirow{2}{*}{ Образец } & \multicolumn{4}{|c}{ Концентрация, at.\% } \\
\cline { 2 - 5 } & {$[\mathrm{C}]$} & {$[\mathrm{O}]$} & {$[\mathrm{N}]$} & {$[\mathrm{Fe}]$} \\
\hline Исходные МУНТ & 92.4 & 2.9 & 3.4 & 1.3 \\
МУНТ, обработанные в плазме & 77.2 & 19.8 & 2.0 & 1.0
\end{tabular}

локальных участках МУНТ достигает $3 \mathrm{~nm}(\sim 8-10$ графеновых слоев). Образование таких дефектов, вероятно, связано с удалением атомов углерода с поверхности МУНТ вследствие окисления. Несмотря на наличие крупных структурных дефектов во внешних графеновых слоях стенки МУНТ, внутренние слои существенных изменений после обработки не претерпели.

По данным РФЭС после обработки плазмой наблюдается значительный рост концентрации кислорода в приповерхностной области образца с $\sim 2.9$ до 19.8 at.\% (см. таблицу). Высокая концентрация кислорода указывает на образование функциональных кислородсодержащих групп на поверхности МУНТ. На рис. 2 представлены спектры C $1 s$-линий углерода массивов МУНТ до и после обработки. В спектре исходных МУНТ (рис. 2,a) основной компонент отвечает $s p^{2}$-углероду $(\mathrm{C}=\mathrm{C} \sim 284.6 \mathrm{eV})$ [9]. Компонент, соответствующий энергии связи $\sim 285.5 \mathrm{eV}$, отвечает гидрогенизированному углероду $(\mathrm{C}-\mathrm{H})$, а также углероду, расположенному вблизи окисленного углерода $\left(\mathrm{C}^{*}-\mathrm{C}(\mathrm{O})\right)$. Компонент 


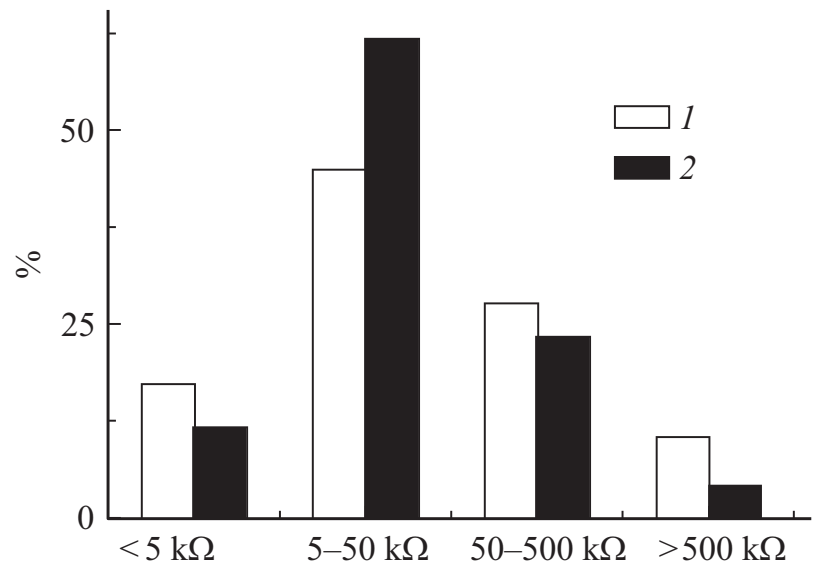

Рис. 3. Диаграмма распределения значений сопротивлений ансамблей исходных МУНТ (1) и МУНТ после обработки в плазме (2).

при $\sim 287 \mathrm{eV}$ соответствует углероду в связи С-O (эпоксидные, гидроксидные, эфирные и другие группы). Также присутствуют компоненты, отвечающие углероду в составе групп $\mathrm{C}=\mathrm{O}$ и $\mathrm{COOH} \mathrm{при} \mathrm{энергиях} \sim 288$ и $289 \mathrm{eV}$ соответственно [10].

После плазменной обработки форма C $1 s$-спектра МУНТ существенно меняется (рис. 2,b), значение полуширины линии увеличивается с 1.61 до $3.62 \mathrm{eV}$, что свидетельствует о повышении гетерогенности химического окружения углерода. В спектре присутствуют интенсивные компоненты с максимумами при энергиях связи $\sim 283$ и $\sim 282 \mathrm{eV}$. Компонент при энергии $\sim 283 \mathrm{eV}$ связан с наличием нескоординированных атомов углерода, расположенных вблизи обрывов графеновых плоскостей [11], что хорошо согласуется с данными ПЭМ, которые показали наличие множественных крупных дефектов структуры вакансионного типа во внешних графеновых слоях. Компонент спектра при $\sim 282 \mathrm{eV}$ может быть связан с присутствием карбидов железа [12], а его появление в спектре может быть обусловлено частичным разрушением внешних графеновых слоев МУНТ и обнажению частиц катализатора, инкапсулированных в вершинах нанотрубок. Также наблюдается снижение относительной интенсивности компонента, отвечающего углерод-углеродным химическим связям $(\mathrm{C}=\mathrm{C})$, с $\sim 80 \%$ для спектра исходных нанотрубок до $40 \%$ после обработки и увеличение интенсивности компонентов, соответствующих структурным дефектам и углеродкислородным группам различного типа (гидроксильным, эпоксидным, эфирным и др.).

На рис. 3 представлены диаграммы распределения значений измеренного сопротивления ограниченных ансамблей МУНТ, расположенных между золотыми контактами. Из диаграммы видно, что основную долю в распределении сопротивлений исходных нанотрубок (рис. 3, распределение 1) представляют ансамбли МУНТ с сопротивлениями от 5 до $50 \mathrm{k} \Omega$, что соответствует литературным данным [13-15]. Существенный разброс значений сопротивлений обусловлен различным количеством нанотрубок в ансамблях и вариативностью внешних диаметров нанотрубок.

После экспозиции в плазме на диаграмме (рис. 3, распределение 2) наблюдается увеличение доли ансамблей нанотрубок с сопротивлением от 5 до $50 \mathrm{k} \Omega$ с $\sim 44$ до $\sim 60 \%$ от общего количества измеренных ансамблей МУНТ. В то же время общая доля ансамблей МУНТ с сопротивлением более $50 \mathrm{k} \Omega$ уменьшилась с $\sim 37$ до $\sim 25 \%$. В целом вид распределения изменился незначительно. Несмотря на наличие на поверхности МУНТ, функционализированных плазмой, большого количества структурных дефектов, увеличения сопротивлений ансамблей МУНТ не наблюдается. Сохранение проводимости МУНТ обусловлено сохранением структуры внутренних графеновых слоев стенок нанотрубок, обеспечивающих транспорт носителей заряда [16]. Мы полагаем, что присутствие нескоординированных углеродных атомов, а также кислородсодержащих групп может обеспечивать образование мостиковых связей на участках контакта отдельных МУНТ, что способно улучшить транспорт носителей заряда.

Приведенные в работе исследования показали, что применение кратковременной обработки Не:О плазмой способствует удалению фрагментов графеновых слоев стенок трубок и формированию рельефа с последующим закреплением функциональных групп различного типа. Изменение структурно-химического состояния поверхности углеродных нанотрубок приводит к сужению распределения значений электрического сопротивления разреженных ансамблей МУНТ. Формирование на поверхности нанотрубок функциональных групп может положительно сказываться на емкостных характеристиках электродных материалов на базе МУНТ и композитов на их основе.

\section{Благодарности}

В работе использовано оборудование Омского регионального центра коллективного пользования СО РАН.

Авторы выражают благодарность Ю.А. Стенькину, М.В. Тренихину и Г.Н. Камаеву за синтез МУНТ и помощь в проведении экспериментов.

\section{Финансирование работы}

Работа выполнена в рамках государственного задания ОНЦ СО РАН (номер госрегистрации проекта 121021600004-7).

\section{Конфликт интересов}

Авторы заявляют, что у них нет конфликта интересов. 


\section{Список литературы}

[1] V.V. Bolotov, P.M. Korusenko, S.N. Nesov, S.N. Povoroznyuk, E.V. Knyazev, Nucl. Instrum. Meth. Phys. Res., 337, 1 (2014). DOI: 10.1016/j.nimb.2014.07.014

[2] А.А. Бурцев, А.А. Павлов, Е.П. Кицюк, Ю.А. Григорьев, А.В. Данилушкин, К.В. Шумихин, Письма в ЖТФ, 43 (11), 88 (2017). DOI: 10.21883/PJTF.2017.11.44701.16570 [A.A. Burtsev, A.A. Pavlov, E.P. Kitsyuk, Yu.A. Grigor'ev, A.V. Danilushkin, K.V. Shumikhin, Tech. Phys. Lett., 43 (6), 542 (2017). DOI: 10.1134/S1063785017060062].

[3] L. An, X. Yang, C. Chang, IJTAN, 1, 30 (2013). DOI: 10.11159/ijtan.2013.004

[4] Н.В. Глебова, А.А. Нечитайлов, Письма в ЖТФ, 36 (19), 8 (2010). [N.V. Glebova, A.A. Nechitailov, Tech. Phys. Lett., 36 (10), 878 (2010). DOI: 10.1134/S1063785010100020].

[5] Ю.А. Положенцева, М.П. Карушев, А.М. Румянцев, И.А. Чепурная, А.М. Тимонов, Письма в ЖТФ, 46 (4), 48 (2020). DOI: 10.21883/PJTF.2020.04.49052.18113 YYu.A. Polozhentseva, M.P. Karushev, A.M. Rumyantsev, I.A. Chepurnaya, A.M. Timonov, Tech. Phys. Lett., 46 (2), 196 (2020). DOI: 10.1134/S106378502002025X].

[6] J. Prashanth, A. Manivannan, N. Prashant, Electrochem. Soc. Interface, 19, 57 (2010). DOI: 10.1149/2.F07103if

[7] Y.H. Yan, J. Cui, M.B. Chan-Park, X. Wang, Q.Y. Wu, Nanotechnology, 18, 115712 (2007). DOI: 10.1088/0957-4484/18/11/115712

[8] С.В. Булярский, В.С. Белов, Е.П. Кицюк, А.В. Лакалин, М.С. Молоденский, А.А. Павлов, Р.М. Рязанов, А.В. Терентьев, А.А. Шаманаев, Письма в ЖТФ, 46 (20), 3 (2020). DOI: 10.21883/PJTF.2020.20.50146.18172 [S.V. Bulyarskiy, V.S. Belov, E.P. Kitsyuk, A.V. Lakalin, M.S. Molodenskii, A.A. Pavlov, R.M. Ryazanov, A.V. Terent'ev, A.A. Shamanaev, Tech. Phys. Lett., 46 (10), 996 (2020). DOI: 10.1134/S1063785020100193].

[9] С.Н. Несов, П.М. Корусенко, В.В. Болотов, С.Н. Поворознюк, Д.А. Смирнов, ФТТ, 59 (10), 2006 (2017). DOI: 10.21883/FTT.2017.10.44972.126 [S.N. Nesov, P.M. Korusenko, V.V. Bolotov, S.N. Povoroznyuk, D.A. Smirnov, Phys. Solid State, 59 (10), 2030 (2017). DOI: $10.1134 / \mathrm{S} 1063783417100286]$.

[10] L.G. Bulusheva, S.G. Stolyarova, A.L. Chuvilin, Yu.V. Shubin, I.P. Asanov, A.M. Sorokin, M.S. Mel'gunov, S. Zhang, Y. Dong, X. Chen, H. Song, A.V. Okotrub, Nanotechnology, 29, 134001 (2019). DOI: 10.1088/1361-6528/aaa99f

[11] Д.Ю. Усачёв, А.В. Фёдоров, О.Ю. Вилков, Б.В. Сеньковский, В.К. Адамчук, Б.В. Андрюшечкин, Д.В. Вялых, ФТТ, 55 (6), 1231 (2013). [D.Yu. Usachov, A.V. Fedorov, O.Yu. Vilkov, B.V. Senkovskiy, V.K. Adamchuk, B.V. Andryushechkin, D.V. Vyalikh, Phys. Solid State, 55 (6), 1325 (2013). DOI: 10.1134/S1063783413060310].

[12] A.K. Bhattacharya, D.R. Pyke, G.S. Walker, C.R. Werrett, Appl. Surf. Sci., 108, 465 (1997).

[13] P. Bazylewski, D.W. Boukhvalov, A.I. Kukharenko, E.Z. Kurmaev, A. Hunt, A. Moewes, Y.H. Lee, S.O. Cholakh, G.S. Chang, RSC Adv., 5, 75600 (2015).

DOI: $10.1039 / C 5 R A 12893 E$

[14] Е.В. Князев, В.В. Болотов, К.Е. Ивлев, С.Н. Поворознюк, В.Е. Кан, Д.В. Соколов, ФТТ, 61 (3), 564 (2019). DOI: 10.21883/FTT.2019.03.47252.259 [E.V. Knyazev, V.V. Bolotov, K.E. Ivlev, S.N. Povoroznyuk, V.E. Kan, D.V. Sokolov, Phys. Solid State, 61 (3), 433 (2019). DOI: $10.1134 / \mathrm{S} 1063783419030168]$.
[15] В.А. Сергеев, Е.С. Климов, И.В. Фролов, ЖТФ, 89 (8), 1223 (2019). DOI: 10.21883/JTF.2019.08.47895.2608 [V.A. Sergeev, E.S. Klimov, I.V. Frolov, Tech. Phys., 64 (8), 1155 (2019). DOI: 10.1134/S1063784219080206].

[16] S. Dehghani, M.K. Moravvej-Farshi, M.H. Sheikhi, Mod. Phys. Lett. B, 26, 1250136 (2012). DOI: $10.1142 / \mathrm{S} 0217984912501369$ 